Hydrology and Earth System Sciences, 4(2), 225-237 (2000) (C) EGS

\title{
Digital terrain analysis of the Haute-Mentue catchment and scale effect for hydrological modelling with TOPMODEL
}

\author{
C. Higy and A. Musy \\ Soil and Water Management Institute, Swiss Federal Institute of Technology, CH-1015 Lausanne, Switzerland \\ e-mail for corresponding author: christophe.higy@epfl.ch
}

\begin{abstract}
It is widely recognised that topography plays an important role in the generation of runoff. The scale of a digital elevation model has been found to have some impacts on the results of hydrological modelling in several studies. In particular it has been shown that the representation of the statistical distribution of the topographic index used by TOPMODEL is sensitive to the scale of the digital terrain model. The objectives of this study are to develop an analysis of the topography and scale effects for the Haute-Mentue catchment and to test the role of different spatial resolution on parameter calibration. The major result is that the spatial scale is important for the parameter values, but not determinant for the modelling results if a pertinent methodology is adopted for the determination of digital watershed representation.
\end{abstract}

Keywords: digital elevation model, topographic index, scale problems, TOPMODEL

\section{Introduction}

During recent decades, the progress realised in computer science and in the development of distributed hydrological modelling has tended to generalise the use of digital terrain representation. Nevertheless, if the debate is now concentrated on the apparent opposition between conceptual and physically-based models, it is relevant not to neglect the importance of the digital elevation treatment, especially the analysis of elevation, slope and catchment area because they are key variables in hydrology. Specifically, they are used to predict the spatial pattern of soil water content (Moore et $a l ., 1991)$. Topography has been studied for a long time with the aim of answering the following question: "How can one choose the best grid size in hydrological modelling?".

This paper presents a study of the role of digital terrain analysis in hydrological modelling with the well-known TOPMODEL (Beven and Kirkby 1979). Similarly, it is shown how to prepare relevant elevation data with a current geographical information system (MAPINFO ${ }^{\circledR}$ ) and demonstrate the role of resolution in hydrological modelling with TOPMODEL, especially with regard to the topographic index. In a second step, a sensitivity analysis of the parameter calibration with respect to space and time resolution is carried out.

\section{The Haute-Mentue research basin and its digital representation}

The Haute-Mentue research basin $\left(12 \mathrm{~km}^{2}\right)$ is located on the Swiss Plateau region $20 \mathrm{~km}$ north of Lausanne. The topography is gently rolling with an average slope of $4^{\circ}$. In terms of meteorological characteristics, the mean annual precipitation is around $1280 \mathrm{~mm}$, the mean annual runoff is $680 \mathrm{~mm}$ and the mean annual potential evapotranspiration is around $600 \mathrm{~mm}$. The climate is humid and temperate. The upper part of the Haute Mentue research basin includes four sub-catchments called Bois-Vuacoz (24 ha), Ruzillon (18.5 ha), Corbamont (58 ha) and Esserts $(32 \mathrm{ha})$. The sub-catchments as a whole are called La Corbassiere (195 ha) (Fig. 1). This study will focus on this catchment.

Before the description of the digital representation of the catchment, two important elements must be introduced. Firstly, the digital elevation model DEM25 (DEM), available for all of Switzerland, is based on the national elevation map at $1: 25,000$, with the resulting interpolated elevations arranged in a 25 -metre square grid. The grid used for this study covers an area of about $12 \mathrm{~km}^{2}$, including 19,320 points. Secondly, a digital terrain model (DTM) has been defined by interpolation 


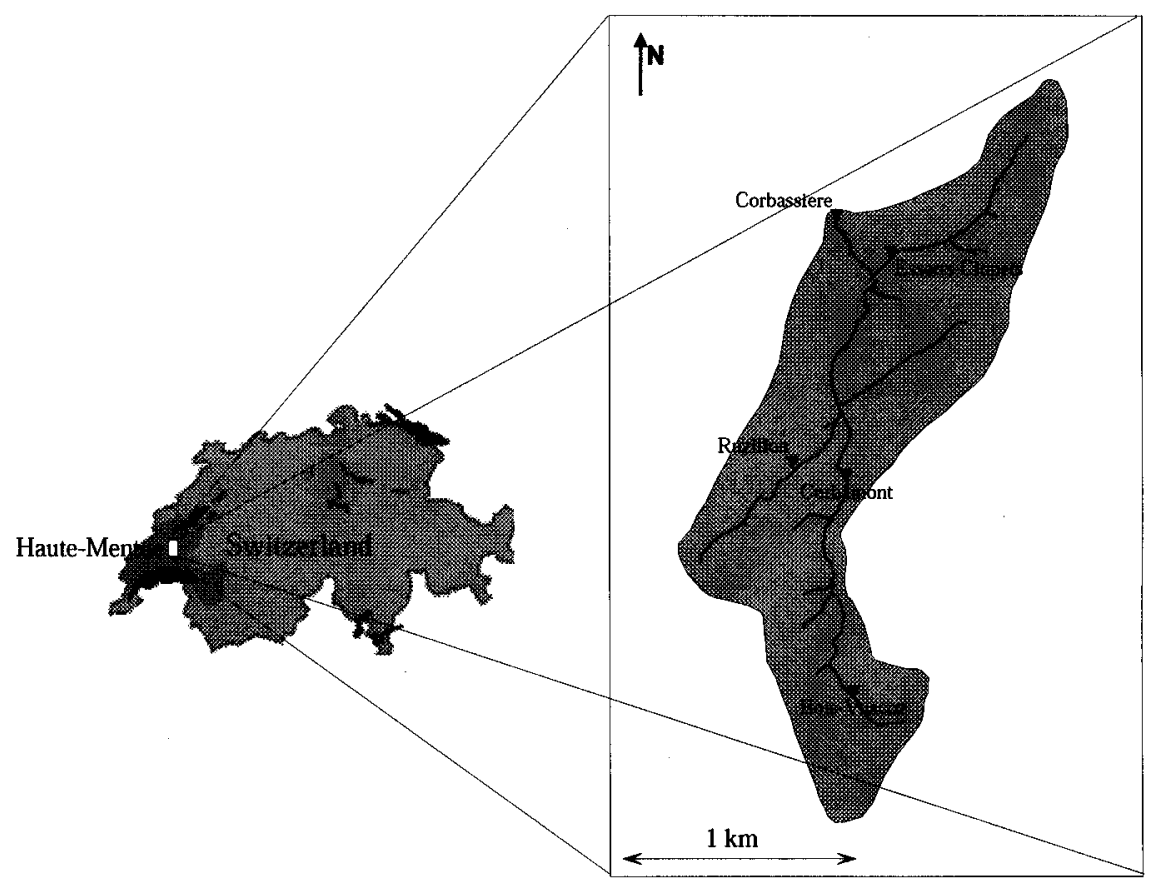

Fig. 1. The upper part of the Haute-Mentue research catchments and situation of the stream gauges for the sub-catchments.

of the DEM over the whole catchment area. The difference between DTM and DEM is explained by the fact that the DEM is the original representation of elements and the DTM results from interpolation at different resolutions. Obviously, the DEM and the DTM for a 25-metre square grid are the same. The methodology proposed here is to interpolate the DEM at a specific resolution before overlaying the DTM with the boundary of the catchment. The advantage of this methodology is that the interpolation of a rectangular grid wider than the catchment implies fewer boundary effects near the perimeter of the catchment. The steps to generate the different DTMs are the following (Fig. 2):

- Importation of DEM in ASCII (text) file.

- Choice of referenced points.

- Computation of the external orientation of the DEM.

- Creation of the triangular irregular network file.

- Derivation of the DTM with a particular grid resolution.

- Overlay with the catchment boundary.
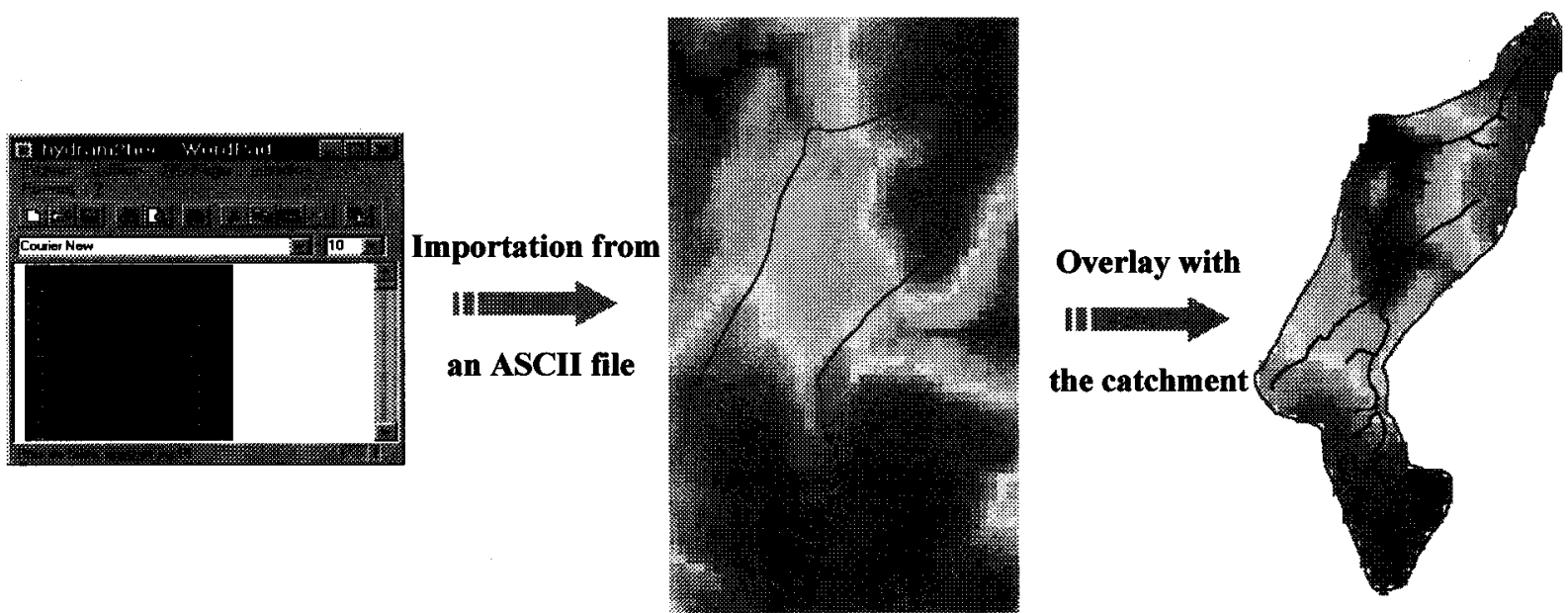

Fig. 2. Methodology used to extract the digital terrain model from the digital elevation model. 


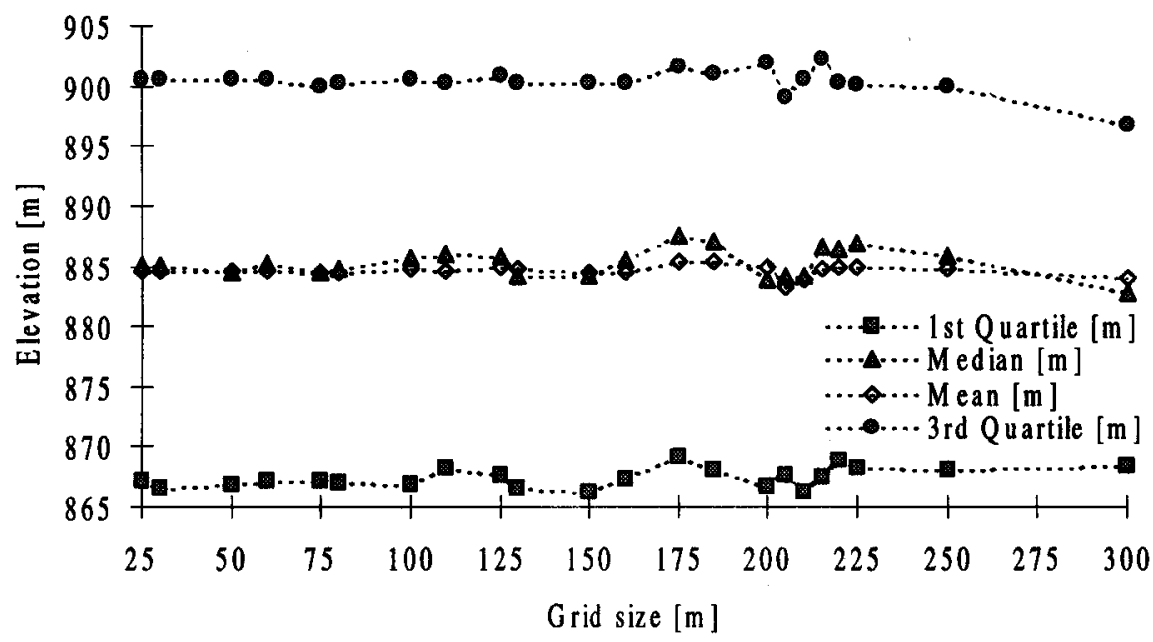

Fig. 3. Evolution of some statistical properties of the elevation with different resolutions.

In this way, DTMs have been generated with a resolution from 25-metre to 300 -metre grid squares.

\section{Sensitivity analysis of the elevation, slope and orientation with respect to spatial resolution}

The first result is the scale effect on the elevation values in the DTM. Figure 3 shows the evolution of some statistical properties for the elevation. We notice that the procedure used is robust in regard to this first result. Some variations are introduced in the 150-metre square grid but they are not significantly different in the statistical sense. In addition, the catchment is relatively small and it begins to be difficult to generate a digital representation with less than 50 cells. Despite this observation, the stability of the estimated catchment area is verified, and the correlation coefficient between the area and the resolution is about 0.33 against -0.92 for previous studies (Bruneau et al., 1995). Figure 4 represents the value of catchment area versus grid size.

With the same approach as in the analysis of the impact of grid size on the elevation values, the effects on the slope angle and orientation of the DTM can be tested. The sensitivity of slope angle is important because the derivation of the topographic index requires this value. The effect of the resolution works as a low-pass filter (Fig. 5). In this case, the correlation coefficient between resolution and the average value of slope is about -0.77 and confirms the low-pass filter effect with an increase of grid size. This result is confirmed by theory because the "smoothing" effect reduces the variability.

In the same way, the sensitivity analysis of orientation with respect to the spatial resolution shows a low-pass filter effect. Furthermore, this effect is observed on two principal components of the distribution of orientation values. In fact, the catchment presents two favoured orientations: East-South-East and West-North-West (Fig 6.).

\section{Sensitivity analysis of the topographic index with respect to spatial resolution}

The sensitivity of the topographic index has received a lot of

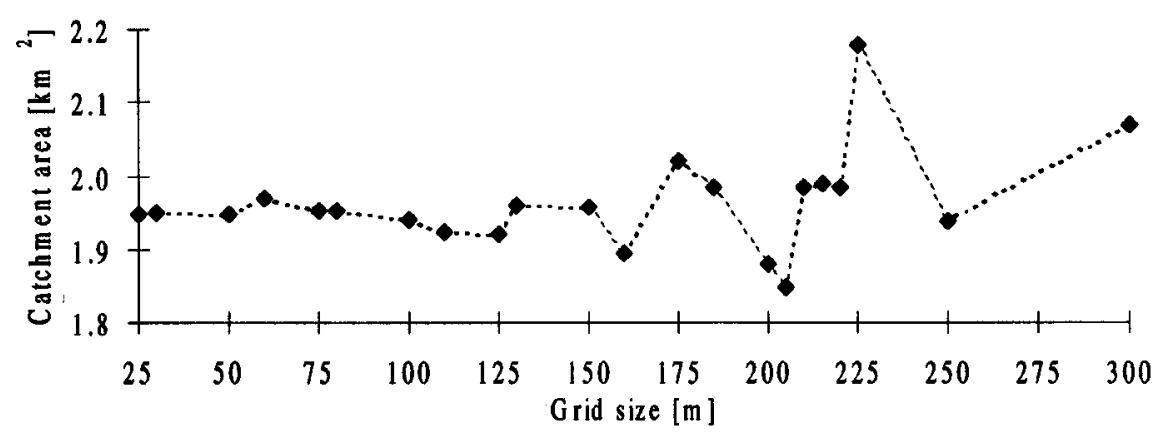

Fig. 4. Catchment area versus grid size. 


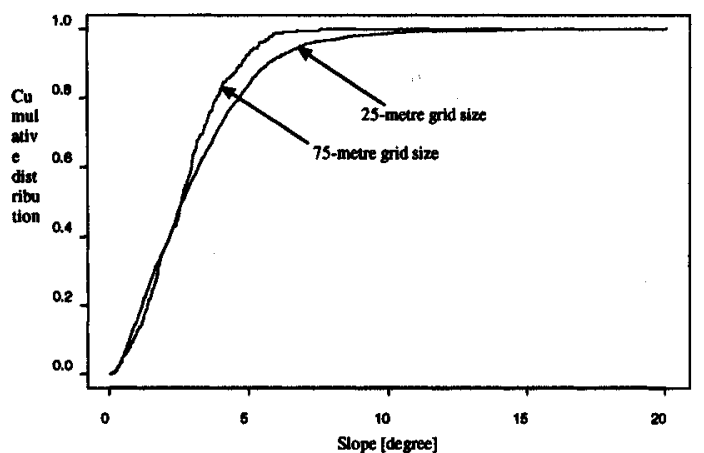

a)

Fig. 5. Comparison of the cumulative distribution of the slope between a) $25 m$ and $75 m$ grid size and $b$ ) $25 m$ and $175 m$ grid size.

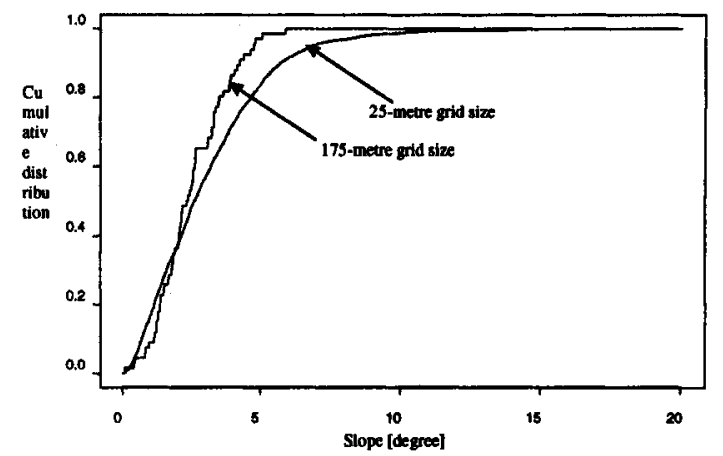

b) attention in the past, and much literature exists about this subject (Band et al., 1995; Franchini et al., 1996; Iorgulescu and Jordan 1994; Jordan and Iorgulescu 1992). In these papers, the authors generally conclude that the topographic index distribution is sensitive to the spatial resolution and to the algorithm used to compute the topographic index (Quinn et al., 1995). In hydrological modelling, these results affect the model parameters which depend on grid size. Typically, the transmissivity parameter increases with increasing the grid size in TOPMODEL. Recently, some studies have pointed out the possibility to compensate for the spatial resolution effect on the hydraulic conductivity (Saulnier et al., 1997). This study begins with a test of the spatial resolution of the topographic index which can be defined by:

$$
I T_{i}=\ln \left(\frac{a_{i}}{\tan \left(\beta_{i}\right)}\right)
$$

where $I T_{i}$ is the topographic index at a location $i$ in the catchment, $a_{i}$ is the upslope area and $\tan \left(\beta_{i}\right)$ is the local slope. In this study, square grids are used ranging from 25-metre to 150-metre. This higher limit is fixed in order to guarantee a sufficient number of meshes to describe the catchment. The analysis of statistical properties of the distribution shows an increase of the minimum and average values of the topographic index with increasing grid size. The correlation between the grid size and the mean value of the topographic index is about 0.98 . This result is significant statistically because the threshold of significance with the risk of failure of $5 \%$ is 0.60 . The same relation is observed with the first and third quartiles of the distribution. In the same manner, the skewness coefficient is constant while the kurtosis coefficient decreases when the grid size increases. The maximum value decreases with an increase in grid size. Conversely, the variance is not very sensitive to the grid size; a correlation coefficient between variance and grid size is -0.1 , whereas the correlation value between kurtosis and grid size is around -0.98 . This result confirms the fact that the distribution of the topographic index is shifted towards high values of the index. In summary, the use of a DTM with an increasing grid size brings about a shift and a shape effect on the topographic index distribution. Thus, for the same value of the topographic index, the proportion of saturated surfaces is larger when the grid size is high. By considering a limiting value of the topographic index of 9 , at a resolution of 25 metres, $20 \%$
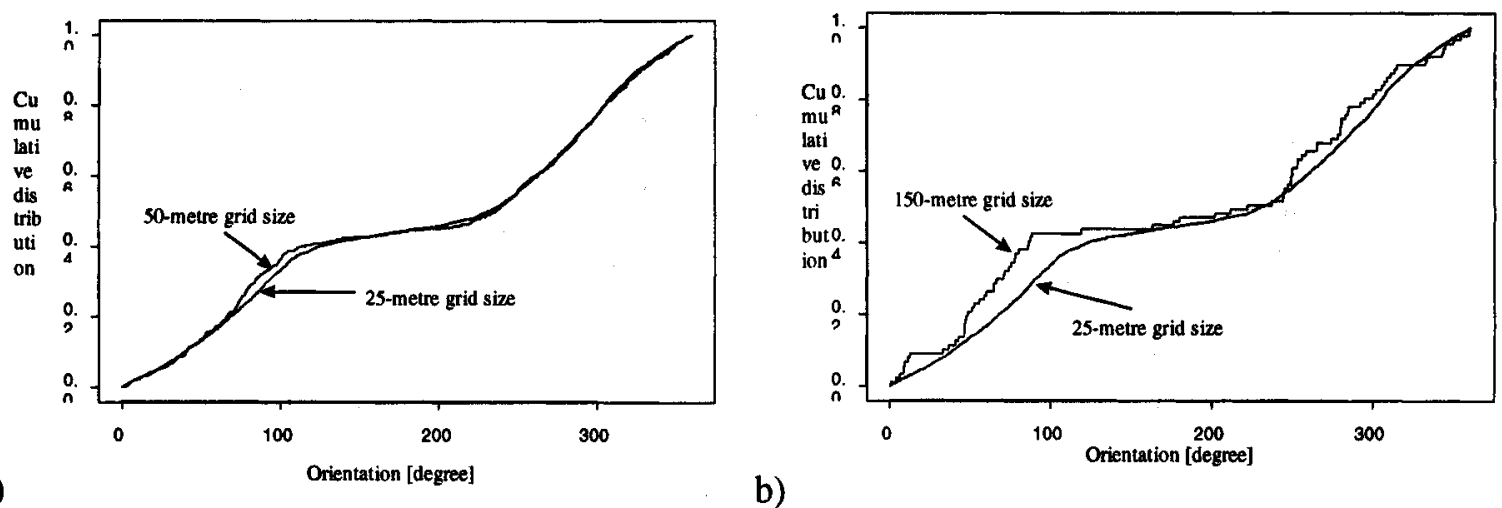

b)

Fig. 6. Comparison of the cumulative distribution of the orientation between a) $25 \mathrm{~m}$ and $50 \mathrm{~m}$ grid size and $\mathrm{b}$ ) $25 \mathrm{~m}$ and $150 \mathrm{~m}$ grid size. 


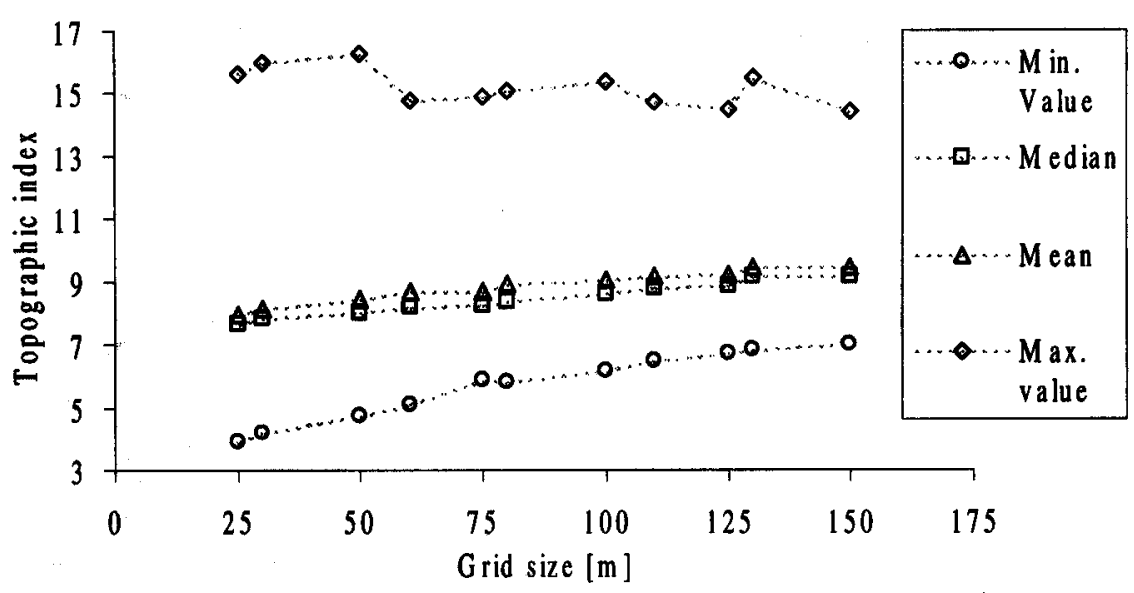

Fig. 7. Sensitivity of the main properties of the topographic index distribution to spatial resolution for la Corbassiere.

of the surface of the basin is saturated, while this value changes to more than $40 \%$ for a grid resolution of 100 metres. The displacement of the mass curves also illustrates the fact that the average value of the topographic index increases as the grid size grows. Furthermore, this implies a propensity for the slope to be permanently saturated.

Some authors have explained this effect by the fact that increasing the grid size gives more importance to the cells situated near the river (Wolock and Price 1994). The overestimation of river cells is verified in la Corbassiere catchment in changing from the 15-metre to 100 -metre grid size, but from $100 \mathrm{~m}$ onwards this phenomenon decreases. This underlines the senselessness of aggregating cells beyond a certain limit because the number of cells crossed by the river are then averaged. Figure 7 shows the evolution of some characteristics of the distribution of the topographic index (minimum, median, mean, maximum) according to the adopted resolution of the digital elevation model. The evolution of the skewness and kurtosis coefficients and variance are presented in Figs. 8 and 9 which illustrate how the grid size affects the topographic index distribution.

In summary, the effect of translation as well as the differences in the relocated cumulative curves are ascribable to the elements which present a strong topographic index, and which are essentially the components of the hydrographic network. Indeed, the elements of the hydrographic network have a low slope as well as a significant drained surface which is over-estimated. This means, as a consequence, that during an increase in the size of DEM mesh, the low-pass filtering of the slopes tends to make the number of elements with strong slope decrease, while one witnesses an increase in the minimum size of the surfaces drained because these cannot be lower than the size of the mesh. It follows the shift towards higher values of topographic index and an increased propensity to saturation for the highest index values, namely those representing the hydrographic network. This is justified by the fact that the proportion of meshes including an element of the hydrographic network increases with an increase in the grid size.

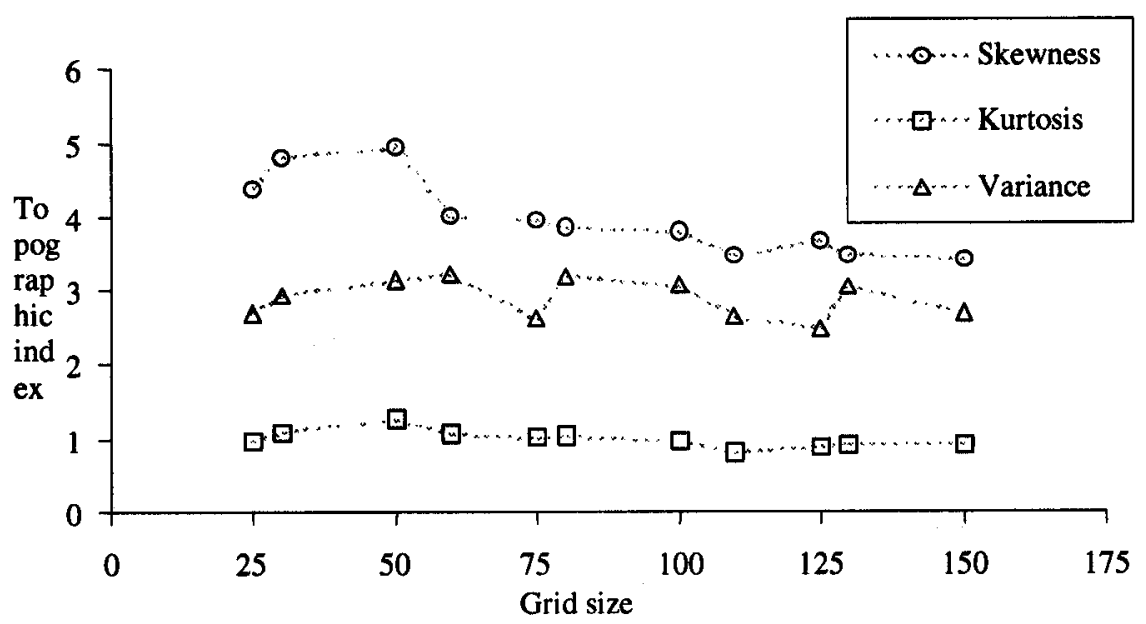

Fig. 8. Sensitivity of the skemness and kurtosis coefficients and variance of the topographic index distribution to spatial resolution for la Corbassiere. 


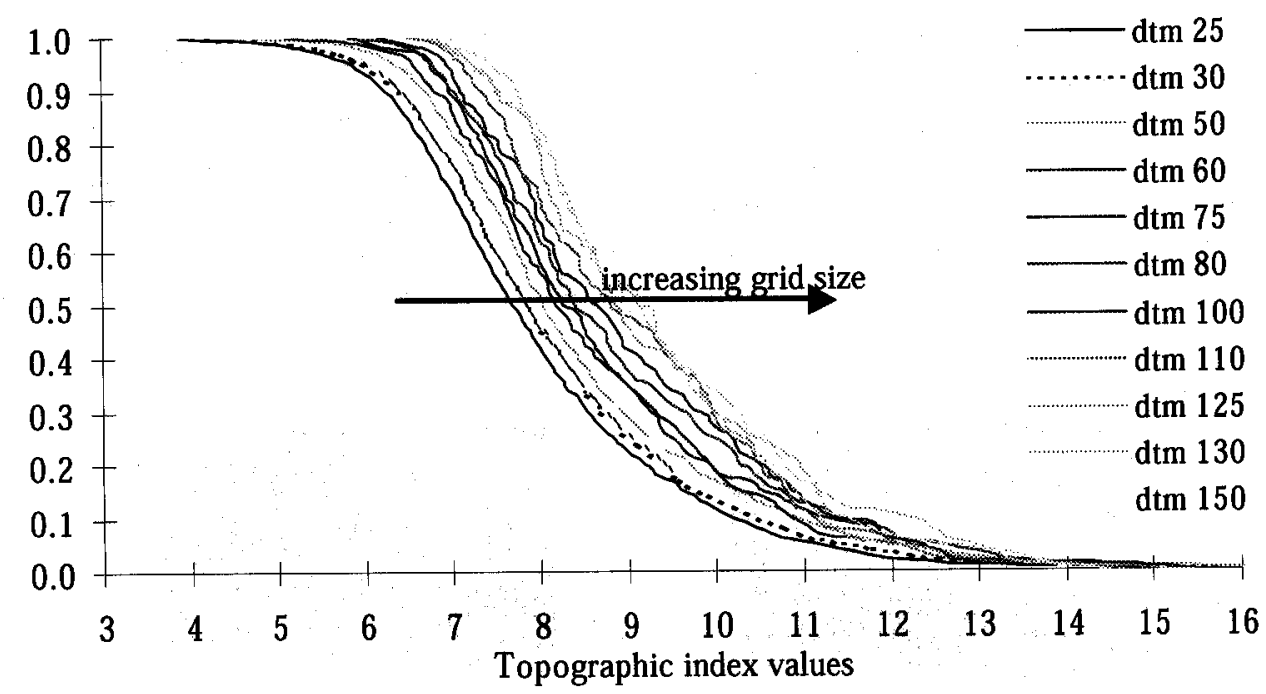

Fig. 9. Sensitivity of the topographic index distribution to spatial resolution for la Corbassiere. Ac is the contributing area, and Ac/A is the fraction of the catchment in a saturated condition.

Table 1. Main characteristics of the period under study from 12.1.1998 to 28.1.1998.

\begin{tabular}{llll}
\hline & Event 1(16.1.1998) & Event 2 (19.1.1998) & Total period \\
\hline Volume of precipitation & $27.85 \mathrm{~mm}$ & $46.76 \mathrm{~mm}$ & $82.66 \mathrm{~mm}$ \\
Volume of surface runoff & $3.38 \mathrm{~mm}$ & $10.17 \mathrm{~mm}$ & $13.55 \mathrm{~mm}$ \\
Volume of total runoff & $6.91 \mathrm{~mm}$ & $15.3 \mathrm{~mm}$ & $53.94 \mathrm{~mm}$ \\
Maximum discharge & $0.31 \mathrm{~mm} / \mathrm{h}=168.09 \mathrm{l} / \mathrm{s}$ & $1.95 \mathrm{~mm} / \mathrm{h}=1057.331 / \mathrm{s}$ & $1.95 \mathrm{~mm} / \mathrm{h}=1057.331 / \mathrm{s}$ \\
Percentage of baseflow & $51.1 \%$ & $33.5 \%$ & $74.9 \%$ \\
Potential evapotranspiration & $0.85 \mathrm{~mm}$ & $0.66 \mathrm{~mm}$ & $5.96 \mathrm{~mm}$ \\
Runoff coefficient & $0.12(3.38 / 27.85)$ & $0.22(10.17 / 46.76)$ & $0.16(13.55 / 82.66)$ \\
\hline
\end{tabular}

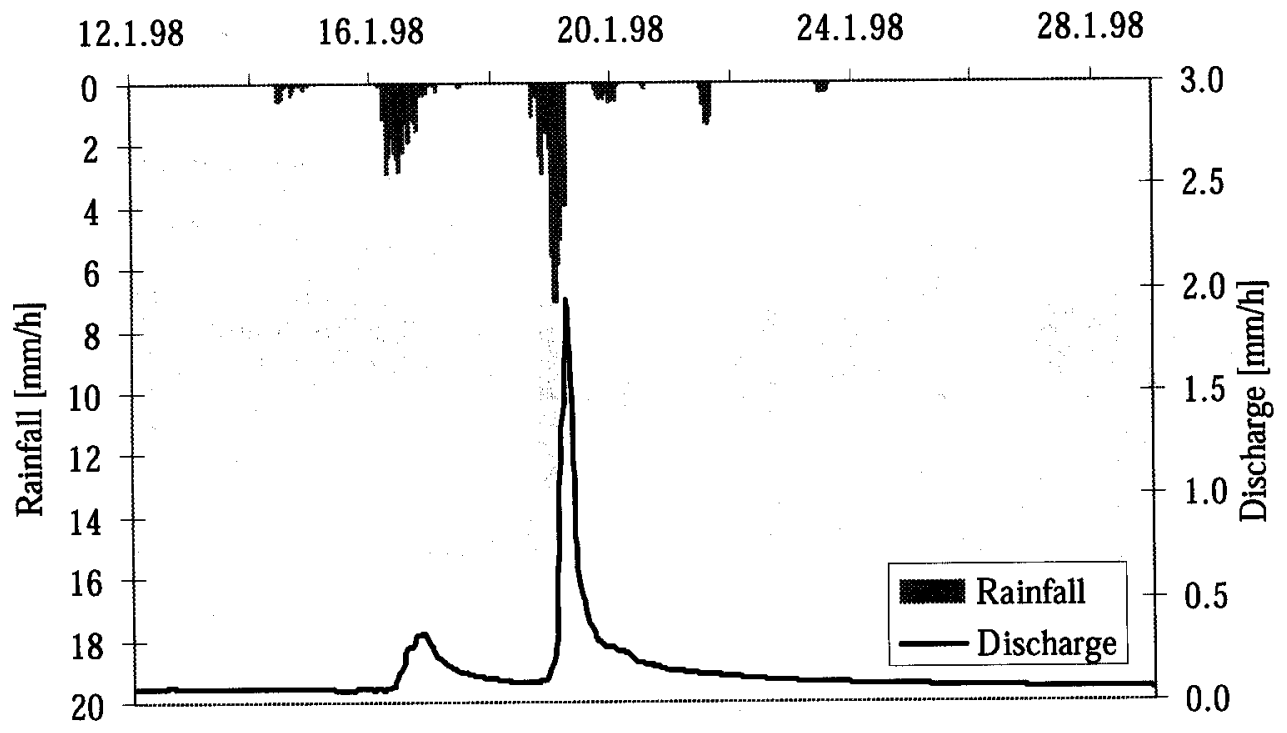

Fig. 10. Rainfall and discharge for la Corbassiere from 12 January to 28 January 1998. 
One can indeed estimate that $8 \%$ of the meshes include an element of the hydrographic network when the resolution is 25 metres, whilst this percentage changes to $17 \%$ for a mesh of 50 metres and to $34 \%$ in the case of a 100 metre mesh. This suggests a necessary consideration of the elements of the hydrographic network in the derivation of the topographic index.

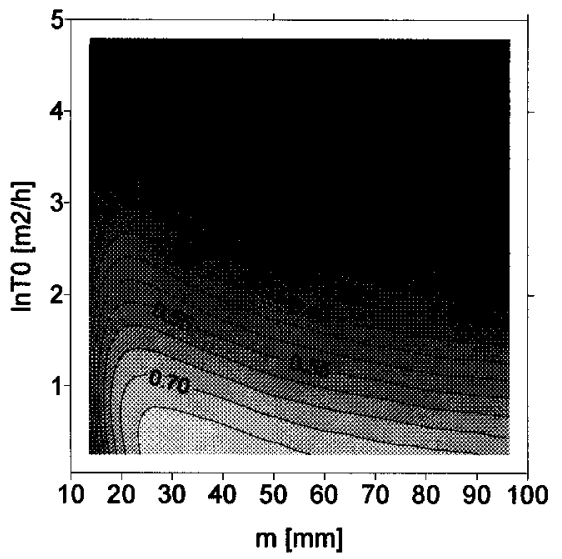

25-metre grid size

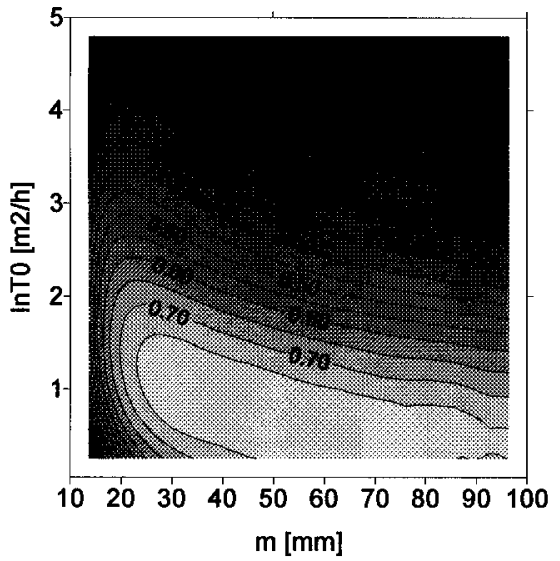

75-metre grid size

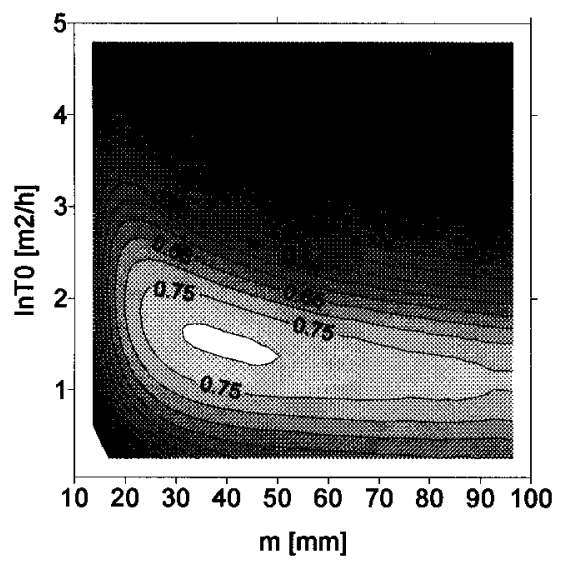

125-metre grid size

\section{Sensitivity analysis in TOPMODEL}

Simulations were first performed for short periods in TOPMODEL with the aim of testing the importance of grid size on the calibration of parameters. So we will not discuss here the quality of the data or the parameter calibration results. The period studied here can be separated into two

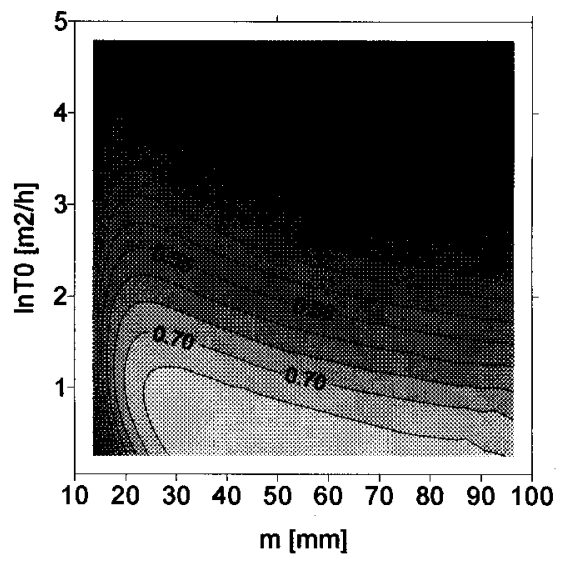

50-metre grid size

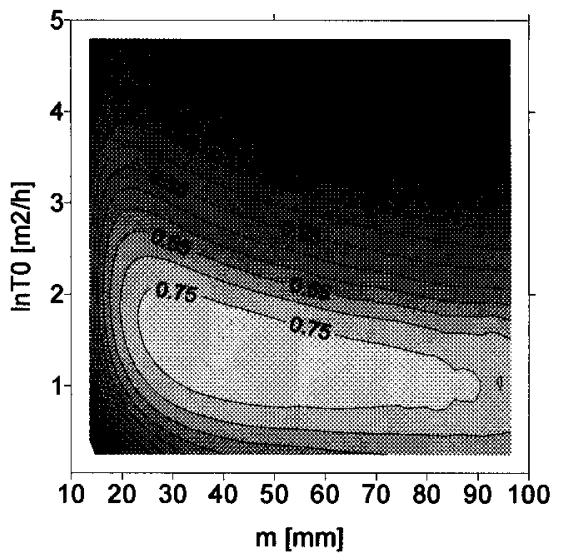

100-metre grid size

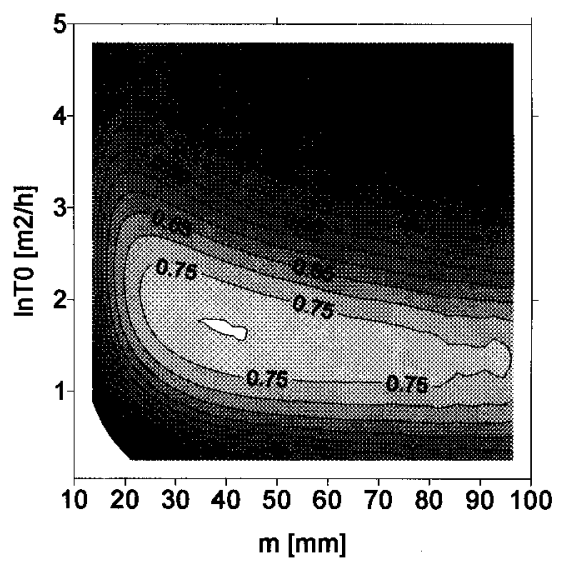

150-metre grid size

Fig. 11. Response surfaces of efficiency for the parameters $\mathrm{m}$ and $\ln \mathrm{T}_{0}$ from 25 to 150 -metre grid size resulting from 5000 Monte Carlo simulations. 


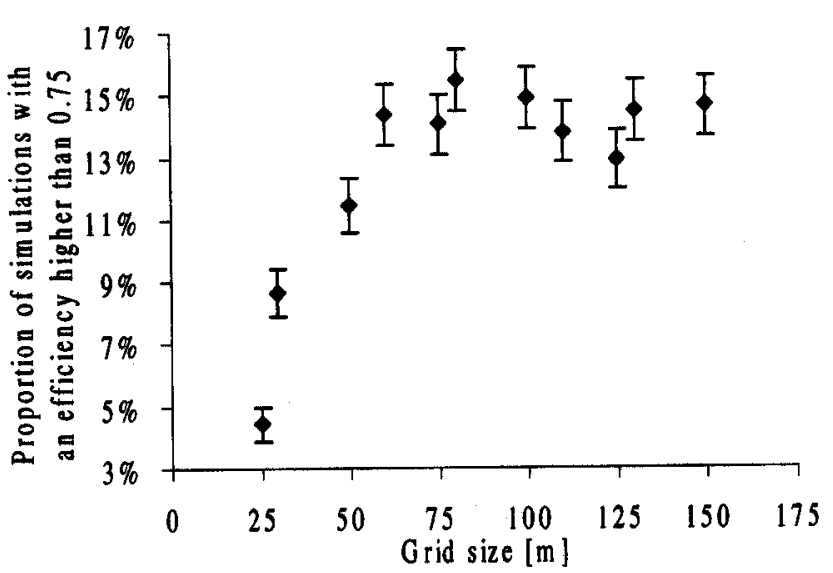

Fig. 12. Proportion of simulations mith an efficiency higher than 0.75 , and 95 .

events. The first occurs on the $16^{\text {th }}$ of January and the second on the $19^{\text {th }}$ of January. The events represented by Fig. 10 are summarised in Table 1.

This version of TOPMODEL has 5 parameters defined as follows (default values for parameters which are kept constant during the Monte Carlo simulations are given in brackets):

$m=\quad$ Parameter of the exponential transmissivity function or recession curve (-).

$\ln \left(T_{0}\right)=$ Logarithm of the transmissivity of the soil at saturation $\left(\mathrm{m}^{2} \mathrm{~h}^{-1}\right)$.

SRmax $=$ Available water capacity of the root zone $(20 \mathrm{~mm})$.

SRinit = Initial root zone deficit (0) (fraction of SRmax).

Chvel $=$ Channel routing velocity $(300 \mathrm{~m} / \mathrm{h})$.

The calibration was done using systematic exploration of the response surface of the objective function for the two most relevant parameters in TOPMODEL, that is to say, the value of transmissivity and the parameter of the

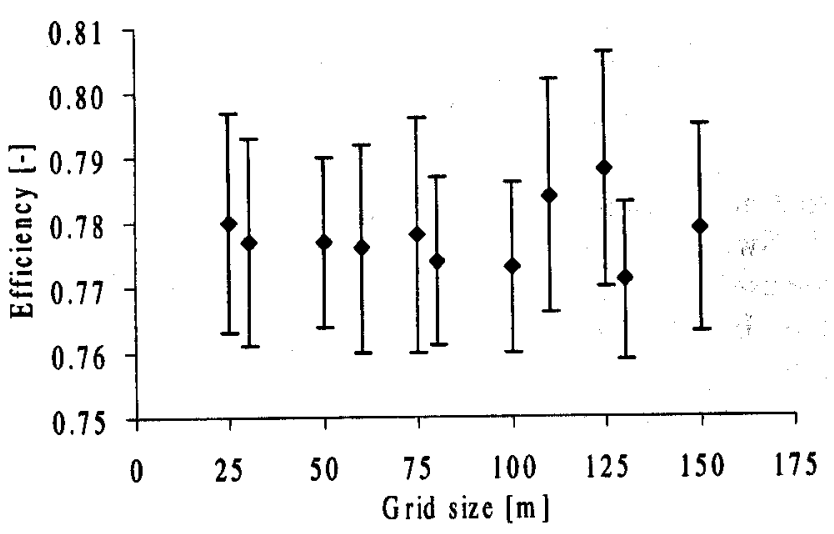

Fig. 13. Average values of efficiencies and their standard deviations for simulations selected according to the resolution of the digital elevation model.

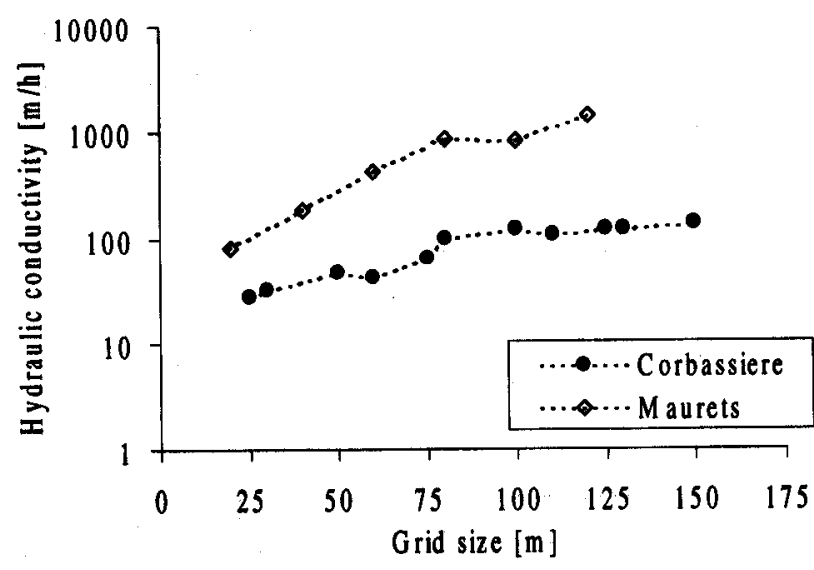

Fig. 14. Sensitivity of the hydraulic conductivity to grid size for the Maurets (from Saulnier 1996) and la Corbassiere catchments (logarithmic scale).

exponential transmissivity. The probability distributions of the parameters are uniform.

The results of the Monte Carlo simulations show
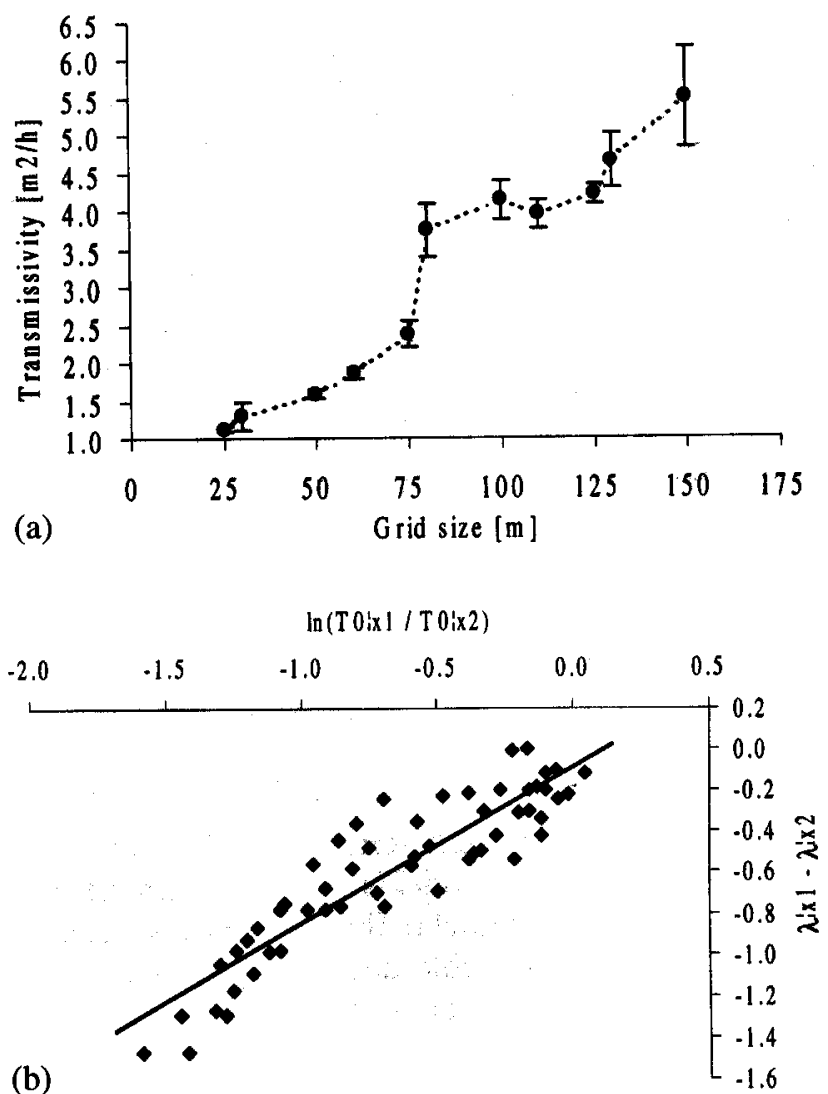

Fig. 15. (a) Sensitivity of transmissivity to grid size for la Corbassiere. The values represented are the average values of the ten best simulations with their standard deviation. (b) Chart of the two terms of Equation 6, with a best fit linear regression of all possible combinations of grid resolution. 
response surfaces for the well-known likelihood function defined by Nash (Nash and Sutcliffe 1970):

$$
e=1-\frac{\sum_{i=1}^{n}\left(Q_{0}(i)-Q_{S}(i)\right)^{2}}{\sum_{i=1}^{n}\left(Q_{0}(i)-\bar{Q}\right)^{2}}
$$

where $Q_{0}(i)$ is the observed discharge, $Q_{s}(i)$ is the simulated discharge and $\bar{Q}$ the average value of observed discharges at time $i$.

The analysis of response surfaces shows that the most sensitive parameter is the transmissivity, and for every grid size it is possible to find a set of parameters which gives the same (or equivalent) efficiency (Fig. 11). The number of simulations with an efficiency higher than 0.75 increases significantly for grid sizes of 80 metres or greater (Fig. 12). This effect is not accompanied by an increase in the average quality of simulations as shown in Fig. 13.

This result shows that the range of simulations with high efficiency grows with the resolution of the digital elevation model for scales from 25 to 80 metre In other words, the surface of good simulations increases between 25 and 80 metres and then becomes stable. In contrast, average efficiency remains independent of the grid size in the digital elevation model.

\section{Effects of grid size on other computed elements}

\section{TRANSMISSIVITY AND HYDRAULIC CONDUCTIVITY}

A brief look at the evolution of transmissivity with grid size shows that, on average, transmissivity increases with grid size. This result was also confirmed by Student's test. The graphical representation of transmissivity (or hydraulic conductivity defined by $K_{0}=T_{0} / m$ ) shows the same behaviour as observed by Saulnier (1996). Figure 14 illustrates this effect with a comparison of the results obtained for a catchment located in the south of France and la Corbassiere. The values represent the average of the ten best simulations. Figure 15 shows the evolution of the transmissivity with modification of the grid size. The

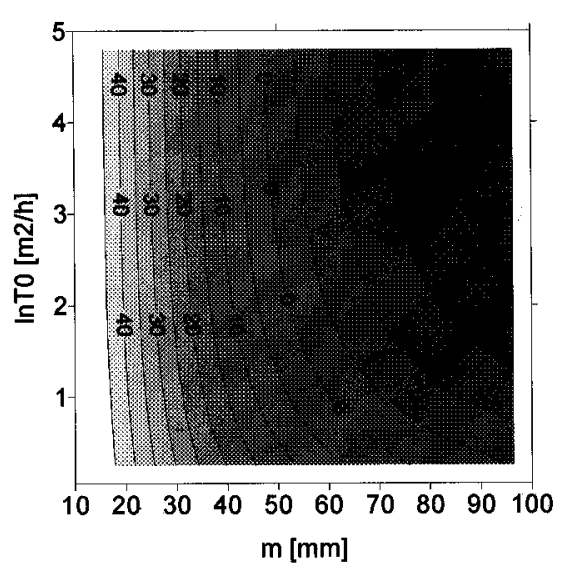

25-metre grid size

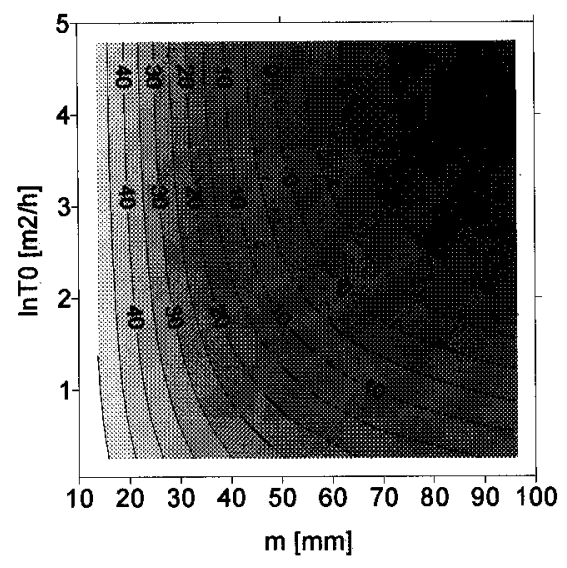

100-metre grid size

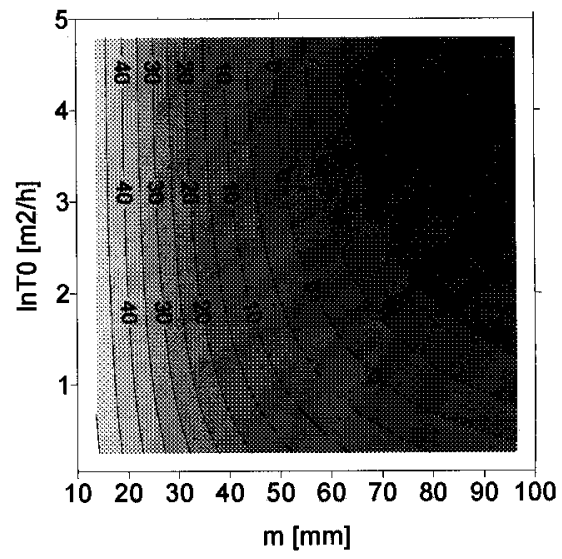

50-metre grid size

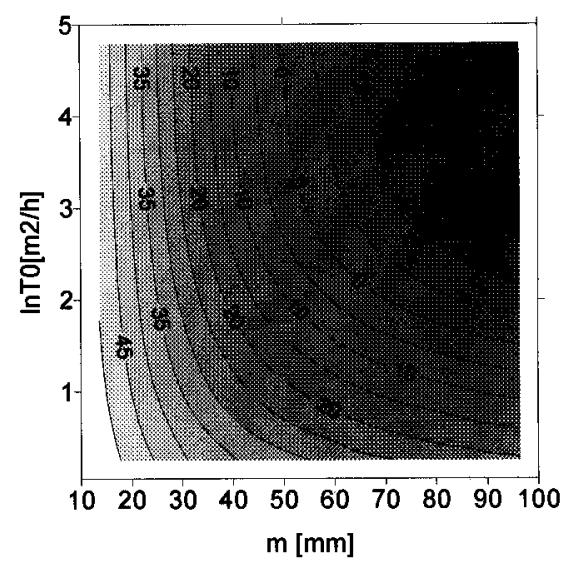

150-metre grid size

Fig. 16. Response surfaces of the relative error in total runoff volume with parameters $\mathrm{m}$ and $\ln \mathrm{T}_{0}$ for different grid sizes. 
transmissivity is shown because of its independence of the parameter $m$. The correlation coefficient between the transmissivity and grid size is about 0.97 , and between the hydraulic conductivity and grid size is 0.95 because of the effect of the non-constant values of the parameter $m$.

By shifting the transmissivity according to the mean value of topographic index, it is possible to find a set of parameters that gives identical efficiencies. This result is also confirmed by the analytical studies of Franchini et al. (1996) and Iorgulescu and Jordan (1994), concerning the interaction between topography, expressed by the topographic index curve, and hydraulic conductivity. Indirectly, this shows the interaction between grid size and transmissivity. In TOPMODEL's theory, the subsurface flow contribution $Q_{b}$ is expressed as (Beven and Kirkby 1979):

$$
Q_{b}=A \cdot T_{0} \cdot \exp (-\lambda) \cdot \exp (-\bar{D} / m)
$$

where $A$ is the area of the catchment, $T_{0}$ the transmissivity when the soil is just saturated, $\lambda$ the mean topographic index, and $D$ the local saturation deficit. This relation can be defined for two different resolutions $\Delta x 1$ and $\Delta x 2$ with the constraint of a constant value of subsurface flow.

$$
\begin{aligned}
\left.Q_{b}\right|_{\Delta x_{1}} & =\left.Q_{b}\right|_{\Delta x_{2}} \\
\left.T_{0}\right|_{\Delta x_{1}} \cdot \exp \left(-\left.\lambda\right|_{\Delta x_{1}}\right) & =\left.T_{0}\right|_{\Delta x_{2}} \cdot \exp \left(-\left.\lambda\right|_{\Delta x_{2}}\right)
\end{aligned}
$$

So the product between transmissivity and the exponential value of the mean topographic index is constant. Equation (5) can be also written as:

$$
\ln \frac{\left.T_{0}\right|_{\Delta x_{1}}}{\left.T_{0}\right|_{\Delta x_{2}}}=\left.\lambda\right|_{\Delta x_{1}}-\left.\lambda\right|_{\Delta x_{2}}
$$

Equation 6 is evaluated for all resolutions examined in this study. The correlation between the left and right hand sides of Eqn. 6 is about 0.91 for the 55 combinations of results.

Equation 5 makes it possible to show that if $\left.\lambda\right|_{\Delta x_{1}}>\left.\lambda\right|_{\Delta x_{2}}$ then $\exp \left(-\left.\lambda\right|_{\Delta x_{1}}\right)<\left(-\left.\lambda\right|_{\Delta x_{2}}\right)$. This implies the following result: $\left.T_{0}\right|_{\Delta x_{1}}<\left.T_{0}\right|_{\Delta x_{2}}$. Thus, the increase in the transmissivity can be understood as a consequence of the structure of the model used. This increase is even more pronounced, as the profile of decrease of transmissivity with depth is exponential. Thus, the hydraulic conductivity of a model

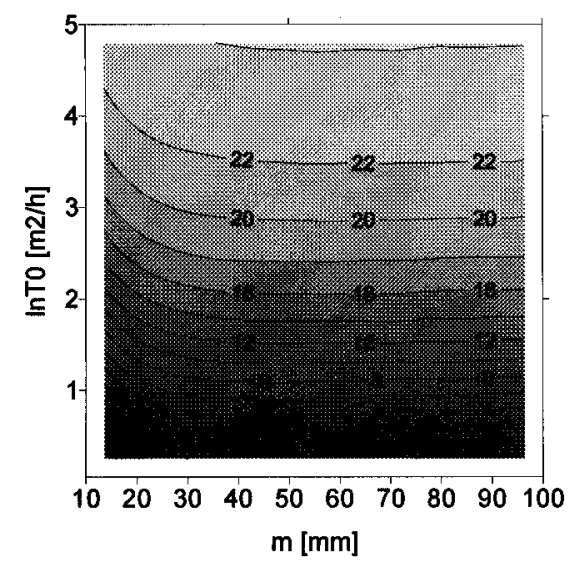

25-metre grid size

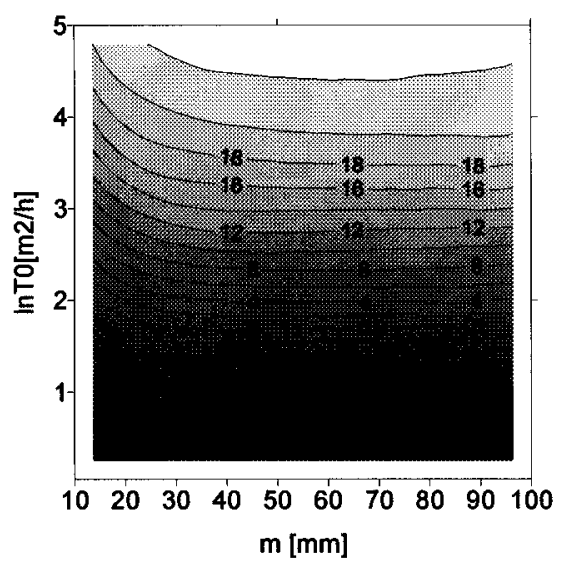

100-metre grid size

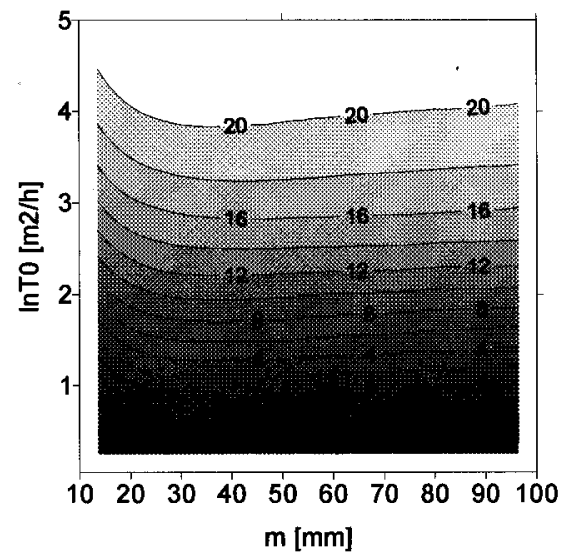

50-metre grid size

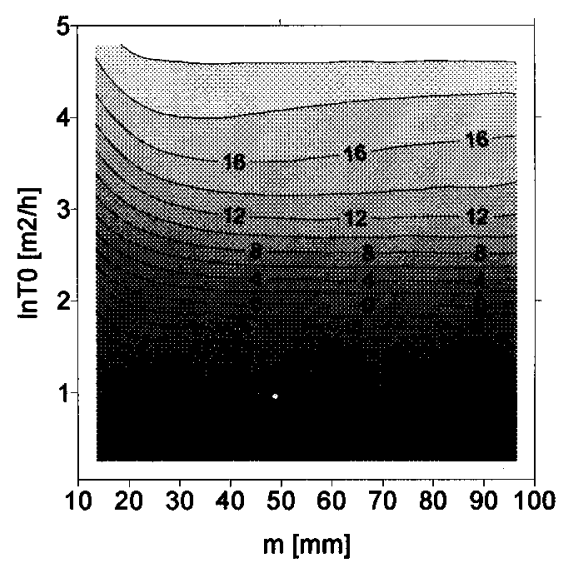

150-metre grid size

Fig. 17. Response surfaces of the absolute error in percentage baseflow volume mith parameters $\mathrm{m}$ and $\ln \mathrm{T}_{0}$ for different grid sizes. 
such as TOPMODEL should not be regarded as the effective hydraulic conductivity of the catchment but as a transfer parameter whose dimensions are that of velocity (length/time). For la Corbassière catchment, the effective values of hydraulic conductivity are about $9.2 \times 10^{-3} \mathrm{mh}^{-1}$ to $8.5 \times 10^{2} \mathrm{mh}^{-1}$ with transmissivity varying between $1.4 \times 10^{-2} \mathrm{~m}^{2} \mathrm{~h}^{-1}$ to $1.3 \times 10^{-1} \mathrm{~m}^{2} \mathrm{~h}^{-1}$ for an average soil depth of $1.50 \mathrm{~m}$ (Higy, 2000). This parameter should be related to the effective hydraulic conductivity of the catchment by means of a relationship which takes into account the grid size, as has already been proposed by Franchini et al. (1996).

\section{RUNOFF VOLUME AND BASE FLOW}

Total runoff volume depends primarily on the parameter $m$ which represents a storage capacity. Thus, an increase in this parameter involves a reduction in runoff volume. Figure 16 shows this effect for various resolutions since the
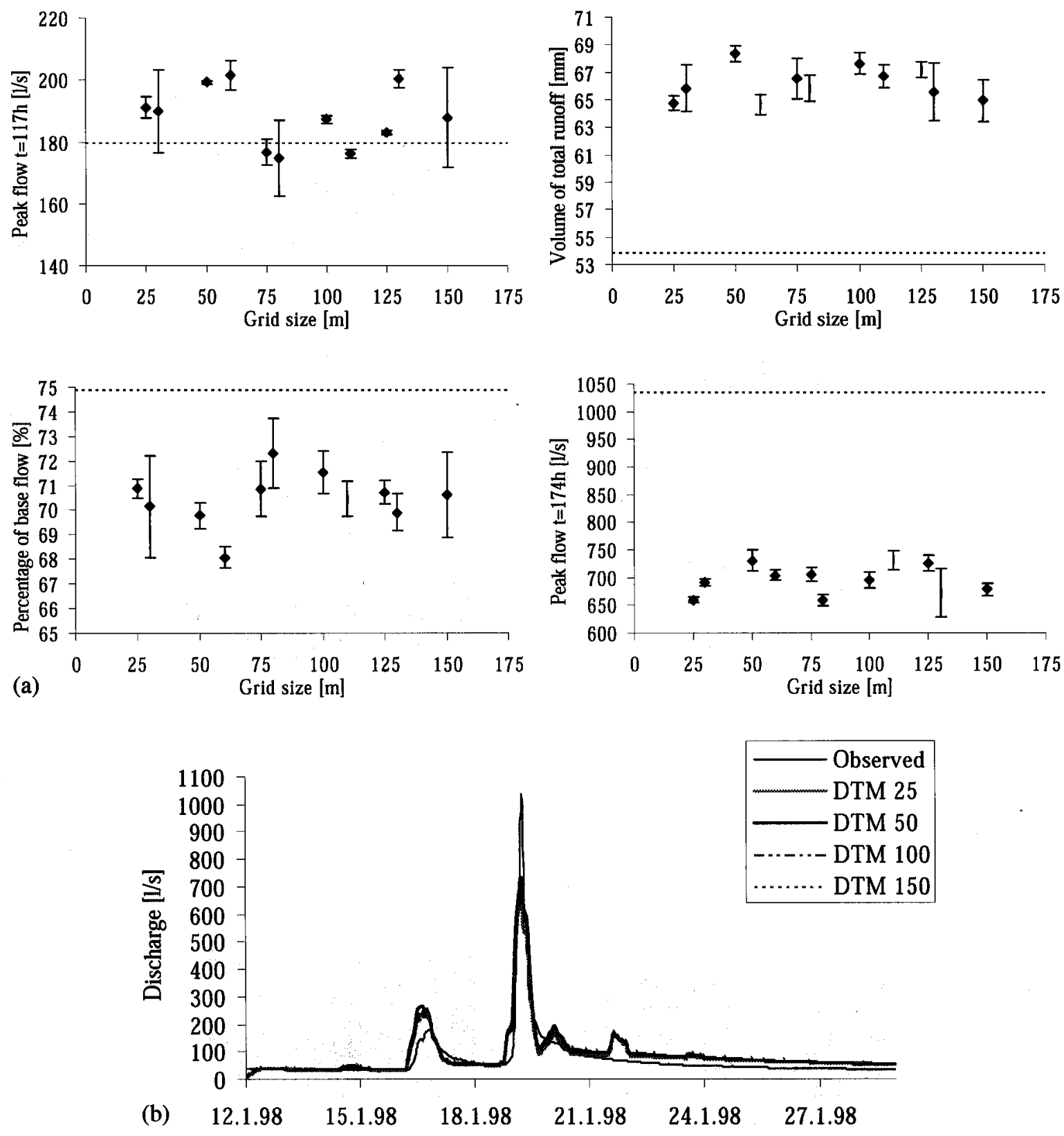

Fig. 18. (a) Sensitivity of the simulated volume of total runoff, simulated peak flow for the first $(t=117 h)$ and second event $(t=174 h)$ and simulated percentage of baseflom to grid size for la Corbassiere. The represented values are the averages of the ten best simulations, mith their standard deviation. The dotted line represents the observed values. (b) Simulated flow for different grid sizes for the complete period. The presented results are obtained with the best set of parameters for each grid size. 


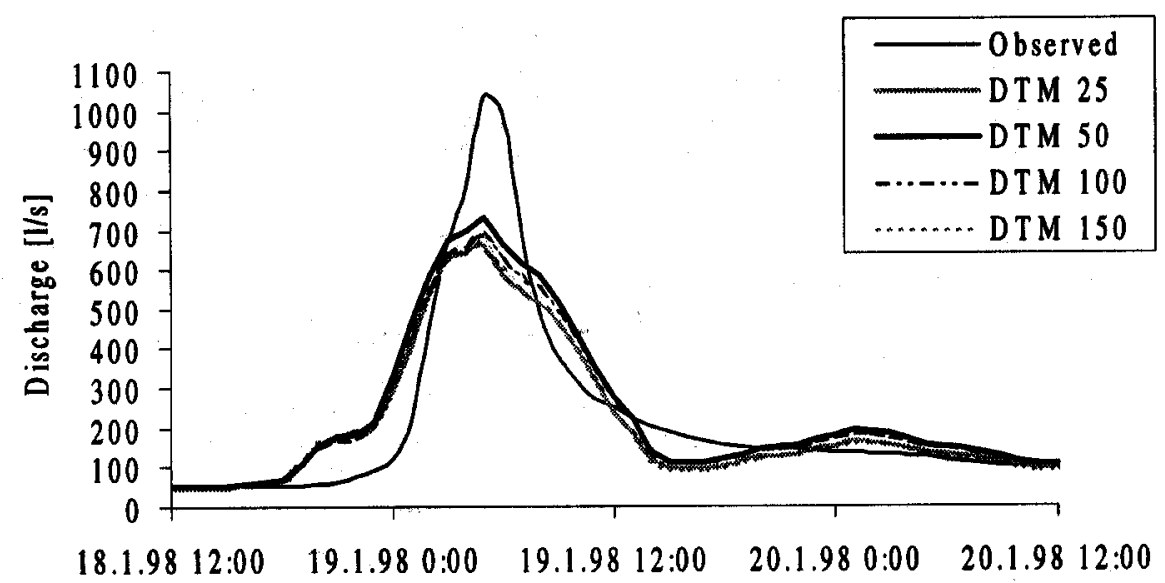

Fig. 19. Simulated flow for the event of 19 January. The results presented are obtained with the best set of parameters for each grid size.

increase in parameter $m$ results in a reduction in the relative error, defined as follows:

$$
e=\frac{V_{s i m}-V_{o b s}}{V_{o b s}} \cdot 100[\%]
$$

One can still notice that the importance of parameter $\ln T_{0}$ increases with the size of the mesh of the digital elevation model. This effect is one of the consequences of the increase in values of $\ln T_{0}$ with grid size. Conversely, the representation of error surfaces of percentage base flow shows a strong sensitivity to parameter $\ln T_{0}$. The increase in transmissivity is accompanied by an increase in the base flow. Furthermore, an increase in the grid size implies an increase in the values of transmissivity as previously observed (Fig 17). The last notable element is the reduction in the surface of minimal error with the increase in the size of the grid.

\section{SIMULATED DISCHARGES}

Concerning simulations carried out, generally the size of the mesh does not affect the results obtained. Thus, simulated volume in the first event is overestimated while the peak flow of the second event is underestimated. The peak flow of the first event is generally simulated in a correct way independently of the grid size. As a consequence, there is an overestimation of total runoff volume and an underestimation of the baseflow due to the greater contribution of overland flow. Figure 18 shows the evolution of the principal elements in relation to the grid size of the catchment. Finally, Figs. 19 and 20 show simulated flows obtained with the best set of parameters $m$ and $\ln T_{0}$ for the complete period and for the second event of January 19. Table 2 gives the numerical values of the parameters of best simulations as well as the efficiency and the average value of the topographic index.

\section{Conclusions and perspectives}

Despite the increasing progress and number of publications relating to applications of TOPMODEL and, in a wider context, with the influence of digital representation of topography in hydrological models, no solution guarantees a physical representation of hydrological parameters after calibration of the model. The practical approach adopted here has shown that it is possible to find a robust way to extract relevant information with a GIS, even if the approach cannot solve the problem of resolution in the computation of topographic index. Despite this effect, the overall scale effect is due essentially to the topographic index calculation.

In the near future, efforts to propose solutions to reduce the dependency of the effective hydraulic conductivity value on the scale have to be proposed, including calculating the topographic index of channel elements as done by Jordan (1992), Iorgulescu and Jordan (1994) and Saulnier et al.

Table 2. Best parameters used for simulations in TOPMODEL.

\begin{tabular}{lllll}
\hline Grid size $[\mathrm{m}]$ & $\mathrm{m}[\mathrm{mm}]$ & $\mathrm{T} 0\left[\mathrm{~m}^{2} / \mathrm{h}\right]$ & Eff $[-]$ & $\lambda[-]$ \\
\hline 25 & 41.5 & 1.13 & 0.807 & 7.98 \\
30 & 34.4 & 1.45 & 0.808 & 8.16 \\
50 & 34.2 & 1.57 & 0.800 & 8.47 \\
60 & 42.9 & 1.91 & 0.809 & 8.67 \\
75 & 41.3 & 2.20 & 0.812 & 8.68 \\
80 & 38.0 & 3.95 & 0.803 & 8.91 \\
100 & 34.9 & 4.19 & 0.805 & 9.03 \\
110 & 36.8 & 4.02 & 0.823 & 9.15 \\
125 & 34.5 & 4.35 & 0.817 & 9.25 \\
130 & 43.1 & 4.87 & 0.792 & 9.45 \\
150 & 43.8 & 5.20 & 0.812 & 9.45 \\
\hline
\end{tabular}


(1997). A more detailed approach to the problems relating to the question of spatial scales should be instigated and a discussion relating to the hydrological process should be proposed. It would be relevant to study these questions thoroughly, in comparison to the possibilities of reducing the number of constraining assumptions in TOPMODEL. Also some problems of internal coherence, such as that related to the assumption of uniform input to the saturated area, and the exponential decrease of the transmissivity profile should be addressed.

\section{Acknowledgements}

This work has been carried out under the VAHMPIRE (Validating Hydrological Models using Process studies and Internal data from Research basins: Tools for assessing hydrological impacts of environmental change ) research programme funded by the EC (Contract No: ENV4-CT950134) and the Swiss Government (Grant OFES\#95.00449).

\section{References}

Band, L.E., Vertessy, R. and Lammers, R.B., 1995. The effect of different terrain representations and resolution on simulated watershed processes. Z. Geomorph. N.F., 101, 187-199.

Beven, K. and Kirkby, M.J., 1979. A physically based variable contributing area model of basin hydrology. Hydrol. Sci. Bull., 24, 43-69.

Bruneau, P., Gascuel-Odoux, C., Robin, P., Merot, P. and Beven, K., 1995. Sensitivity to space and time resolution of a hydrological model using digital elevation data. Hydrol. Proc., 9, 69-81.

Franchini, M., Wendling, J., Obled, C. and Todini, E., 1996. Physical interpretation and sensitivity analysis of the TOPMODEL. 7. Hydrol., 115, 293-338.

Higy, C., 2000. Modélisations conceptuelles et á base physique des processus hydrologiques: Application au bassin versant de la Haute Mentue. Thèse no 2148, EPFL, Lausanne.

Iorgulescu, I. and Jordan, J.-P., 1994. Validation of TOPMODEL on a small Swiss catchment." 7. Hydrol., 159, 255-273.

Jordan, J.-P., 1992. Identification et modélisation des processus de génération des crues. Application au bassin versant de la HauteMentue. Thése no 1014, EPFL, Lausanne.

Jordan, J.-P. and Iorgulescu, I., 1992. Problèmes d'échelle dans les relations pluie-débit d'un petit bassin versant. Rencontres hydrologiques franco-roumaines, Paris.

Moore, I.D., Grayson, R.B. and Ladson, A.R., 1991. Digital terrain modelling: a review of hydrological, geomorphological, and biological applications. Terrain Analysis and Distributed Modelling in Hydrology, K.J. Beven, I.D. Moore, eds., Wiley, Chichester, UK, 7-34.

Nash, J.E. and Sutcliffe, J.V., 1970. River flow forecasting through conceptual model. Part 1 - a discussion of principles. $\mathcal{F}$. Hydrol., 10, 282-290.

Quinn, P., Beven, K. and Lamb, R., 1995. The $\ln (\mathrm{a} / \mathrm{tgb})$ index: How to calculate it and to use it within the TOPMODEL framework. Hydrol. Proc., 9, 161-182.

Saulnier, G.M., 1996. Information pédologique spatialisée et traitements topographiques améliorés dans la modélisation hydrologique par TOPMODEL. Thése de doctorat, Institut Polytechnique de Grenoble.

Saulnier, G.M., Beven, K. and Obled, C., 1997. Digital elevation analysis for distributed hydrological modeling: Reducing scale dependence in effective hydraulic conductivity values. Wat. Res. Res., 33, 2097-2101.

Wolock, D.M. and Price, C.V., 1994. Effects of digital elevation model map scale and data resolution on a topography-based watershed model. Wat. Res. Res., 30, 3041-3052. 